\title{
Compensation claims for chiropractic in Denmark and Norway 2004-2012
}

Jørgen Jevne ${ }^{1}$, Jan Hartvigsen ${ }^{2,3^{*}}$ and Henrik Wulff Christensen ${ }^{3}$

\begin{abstract}
Background: Adverse events are commonly observed in all parts of health care and have been reported extensively following manual therapy, including chiropractic. The majority of reported adverse events following chiropractic care are mild, transitory and self-limiting. However, little is known about patient filed compensation claims related to the chiropractic consultation process. The aim of this study was to describe claims reported to the Danish Patient Compensation Association and the Norwegian System of Compensation to Patients related to chiropractic from 2004 to 2012.

Methods: All finalized compensation claims involving chiropractors reported to one of the two associations between 2004 and 2012 were assessed for age, gender, type of complaint, decisions and appeals. Descriptive statistics were used to describe the study population.

Results: 338 claims were registered in Denmark and Norway between 2004 and 2012 of which 300 were included in the analysis. 41 (13.7\%) were approved for financial compensation. The most frequent complaints were worsening of symptoms following treatment $(n=91,30.3 \%)$, alleged disk herniations $(n=57,19 \%)$ and cases with delayed referral $(n=46,15.3 \%)$. A total financial payment of $€ 2,305,757$ (median payment $€ 7,730$ ) were distributed among the forty-one cases with complaints relating to a few cases of cervical artery dissection ( $n=11,5.7 \%)$ accounting for $88.7 \%$ of the total amount.
\end{abstract}

Conclusion: Chiropractors in Denmark and Norway received approximately one compensation claim per 100.000 consultations. The approval rate was low across the majority of complaint categories and lower than the approval rates for general practioners and physiotherapists. Many claims can probably be prevented if chiropractors would prioritize informing patients about the normal course of their complaint and normal benign reactions to treatment.

Keywords: Compensation claims, Chiropractic, Manual therapy, Adverse events, Side effects

\section{Background}

The prevalence of adverse events (AE) following treatments is often overlooked when considering the overall effectiveness of an intervention. In spite of numerous high-quality trials published each day, the majority of these primarily focus on treatment effects and do not prioritize the reporting of $\mathrm{AE}$ [1]. Consequently, systematic reviews reporting on $\mathrm{AE}$ are generally lacking, accounting for only $10 \%$ of all reviews published [2]. The

\footnotetext{
* Correspondence: jhartvigsen@health.sdu.dk

${ }^{2}$ Department of Sports Science and Clinical Biomechanics, Faculty of Health Sciences, University of Southern Denmark, Campusvej 55, DK-5230 Odense M, Denmark

${ }^{3}$ Nordic Institute of Chiropractic and Clinical Biomechanics, Campusvej 55, DK-5230 Odense M, Denmark

Full list of author information is available at the end of the article
}

fact that many trials fail to report AE, may lead clinicians to believe that an intervention is harmless, when in reality its safety is unknown [3]. Accurate information on harms is imperative for evidence-based practice and as such AE should be reported from all parts of medicine [4]. Within musculoskeletal care, a plethora of $\mathrm{AE}$ have been published with regards to spine surgery [5], hip and knee surgery [6-9], corticosteroid injections [10,11], pharmacological therapy [12] exercise and physiotherapy [13-15] and manual therapy (MT) $[16,17]$.

MT is an umbrella term covering a wide range of manual techniques and treatments including spinal manipulative therapy (SMT), mobilization and different soft-tissue techniques. Chiropractors, general practioners (GPs), physiotherapists and other manual therapists are 
among the health care professionals delivering MT. It is generally considered to be a safe and effective treatment option for patients with a range of musculoskeletal conditions [18]. However, a large number of mild AE have been reported and it is estimated that approximately $50 \%$ of patients will experience at least one adverse reaction during the course of treatment $[16,17,19]$.

Particular controversy surrounds SMT [20,21], a MT procedure involving a high-velocity low amplitude thrust manoeuvre directed primarily towards the spine [22]. Earlier studies have shown that chiropractors are among practitioners who use SMT extensively, primarily for treatment of neck and low back pain [23]. The reports on adverse events following SMT range form mild, transitory discomfort $[24,25]$ to serious, adverse events including stroke and death [26,27]. Some authors have advocated that there exists a massive under-reporting of serious injuries and that the risks associated with chiropractic treatment are much larger than previously thought [27]. In contrast, others have pointed to cases of misreporting in the medical literature, suggesting overreporting of complications following chiropractic care, when clinicians are wrongly identified as chiropractors $[28,29]$. Furthermore, a recent study found that a large portion of AE commonly observed following chiropractic care may be the result of non-specific effects and natural history variation and not related to the treatment [30]. The concept of non-specific effects causing AE is not new [31], and this phenomenon has been observed in other clinical trials, where AE were noted following placebo treatments [32,33]. Clearly our current understanding of AE following MT is limited. Carnes et al. defined AE in manual therapies in 2010 through a modified Delphi consensus study [34] and concluded that reaching a consensus definition remains challenging.

The Danish Patient Compensation Association (DPCA) is the institution responsible for assessment of compensation claims following medical treatments performed by authorized health care personnel in Denmark. Since 2004, this has been the avenue for chiropractic patients and clinicians to report $\mathrm{AE}$ following chiropractic care if a financial compensation is considered relevant. In Norway, a similar system has existed since 2009 through the Norwegian System of Compensation to Patients (NSCP). An overview of registered claims to the two associations is available through their corresponding websites $[35,36]$. While reports on AE following MT are frequently published, our knowledge regarding the types of compensation claims reported from this field is limited. It should be noted, that while definitions of AE exist [34], compensation claims remain a different entity. Therefore, while it is impossible not to touch upon the field of AE, this paper is primarily concerned with compensation claims related to potential financial reimbursements after patient injury reports.
The purpose of this study was to report on the number and types of claims following consultation with chiropractors reported to the Danish and Norwegian compensation associations. Furthermore, we calculated age and gender distributions for the reported claims. Lastly, we assessed approval rates, appeals and financial compensations.

\section{Methods}

\section{Study design}

A retrospective study of compensation claims following consultations with chiropractors reported to the Danish and Norwegian compensation associations.

\section{Case selection}

Eligible cases were registered with DPCA and NSCP between January 1st 2004 and December 31st 2012 and January 1st 2009 and December 31st 2012, respectively. Cases were included if they involved a chiropractor and they were finalized at the time of this review. Cases were excluded if the patient insurance law did not cover them, if patients withdrew claims, if claims were wrongly assigned to chiropractors, or if data were duplicates or missing.

\section{Data collection}

The authors made direct contact with DPCA and NSCP independently. Microsoft Excel spread sheets were provided individually from the two associations containing data on each individual case during the time period. Spread sheets were provided in their raw form, and the first author individually assessed each case. When details were missing from the spread sheet, individual case files were manually accessed through a database and outstanding issues were resolved.

\section{Assessment of claims}

Claims are assessed somewhat differently in Denmark and Norway, however both countries have a no fault system implying that the health care professional is not personally liable for accidents or injuries occurring in the office even in cases of negligence. In Denmark, cases are assessed based on criteria known as the specialist standard and the rule of reason. Specialist standard implies that a state-of-the-art procedure for the professional group in question was followed in every aspect of the consultation. If the clinician did not fullfill this standard, the patient likely receives compensation because the injury could potentially have been prevented if the clinician had adhered to this standard. The rule of reason implies that if a patient leaves the office of a health care professional in a worse condition than they entered under the given consultation complaint, they may receive compensation even in cases where the health care professional adhered to the specialist standard. This rule 
applies for instance in cases of cerebrovascular accidents occurring following cervical spine manipulation, where the primary complaint might be neck pain, even when no causal connection can be established. Thus, approved compensation for a claim does not imply causality or lack of judgement by the clinician but is a reflection of the statutory function of the compensation association.

In Norway certain criteria must be fulfilled in order to receive financial compensation: (1) There has to be a causal relationship between the treatment provided and the observed injury; (2) treatment should clearly not have been provided as there were clear signs of contraindication; (3) there has to be a financial loss because of the injury.

\section{Variables}

Variables retained and included in this paper:

- Age

- Gender

- Registered date for claim and date for final decision

- Complaint categories

- Worsening of symptoms - patients reported aggravated symptoms following treatment

- Alleged disk herniation - patients claimed disk herniations had been induced because of treatment

- Delayed referral - the chiropractor failed to refer the patient for adequate treatment

- Newly developed symptoms/injury following treatment

- Treatment induced fracture - patients reported treatment(s) resulting in bone fractures excluding cases concerning fractured ribs

- Cervical artery dissection (CAD) - injuries related to either the internal carotid or the vertebral arteries

- Rib injury (including fractures) to the rib(s) or associated cartilage

- Accidents - minor unforeseen events such as patients falling off the treatment table

- Miscellaneous such as alleged nerve and organ injuries

- Decisions (approved or rejected for financial compensation)

- Financial compensation (calculated in $€ E U R$ )

- Appeals

- All claims can be appealed by the patient, either for approval if rejected or, if approved, for a higher financial compensation

Comparable claims were summarized and defined under the appropriate complaint category. Similar types of complaints constituting five or less cases were considered to be infrequent and categorized under miscellaneous.

\section{Analyses}

First the annual complaint rate was calculated for Denmark and Norway individually based on registered time of claim. Then the study population was described with regard to age and gender using frequencies and proportions and for Denmark reported in relation to the annual distribution of patients in Danish chiropractic practice [37]. The overall annual frequency of claims and the annual approval rate was calculated for the two countries. Subsequently, complaints were categorized into complaint categories, which were tabulated and approval rates and financial compensations were calculated for each category. Lastly, claims were categorized based on the body region primarily treated and approval rates and financial compensations were reported based on these.

\section{Ethics}

The spread sheets were anonymous and did not contain information that could identify the patient or chiropractor in question. In cases where details were missing and the database had to be accessed, sensitive information was available but was not withdrawn from the database or used in any way. The first author signed a confidentiality agreement before gaining access to the database.

\section{Results}

From 2004-2012 a total of 338 claims were filed to DPCA $(n=288)$ and NSCP $(n=50) .38$ cases were excluded for the following reasons: 20 were not completed at the time of review, 9 were not covered by the patient insurance law, 3 cases had incomplete data, in 3 cases the patient withdrew the claims, 2 cases involved nonchiropractors, and one case was a duplicate. Thus, a total of 300 claims were included in the analyses, 269 from DPCA and 31 from NSCP (Figure 1).

The annual rate of claims remained fairly stable during the period. The highest number observed in Denmark was in $2009(n=42)$ and in Norway in $2012(n=13)$ (Figure 2). Of the 300 included claims there were 166 (55.3\%) females and 134 (44.7\%) males. 217 patients were aged $31-60$ years, accounting for $72.3 \%$ of the total study population. Statistics from 2012, suggests 57.9\% of Danish chiropractic patients belong in this age interval [37]. The age distribution ranged from 11 to 80 years in the study population, in contrast to the annual patient population ranging from 0 to 99 years [37] (Figure 3).

Of 300 included claims, only 41 (13.7\%) were eventually approved for financial compensation. Among the approved claims, 39 were from DPCA and the remaining two from NSCP. 32 of the 41 approved claims were directly approved following appraisal, while the remaining 9 were approved following appeals. A relatively stable approval rate was observed, ranging from its highest in 2004 (25\%) to its lowest in 2010 (6.5\%) (Table 1). 


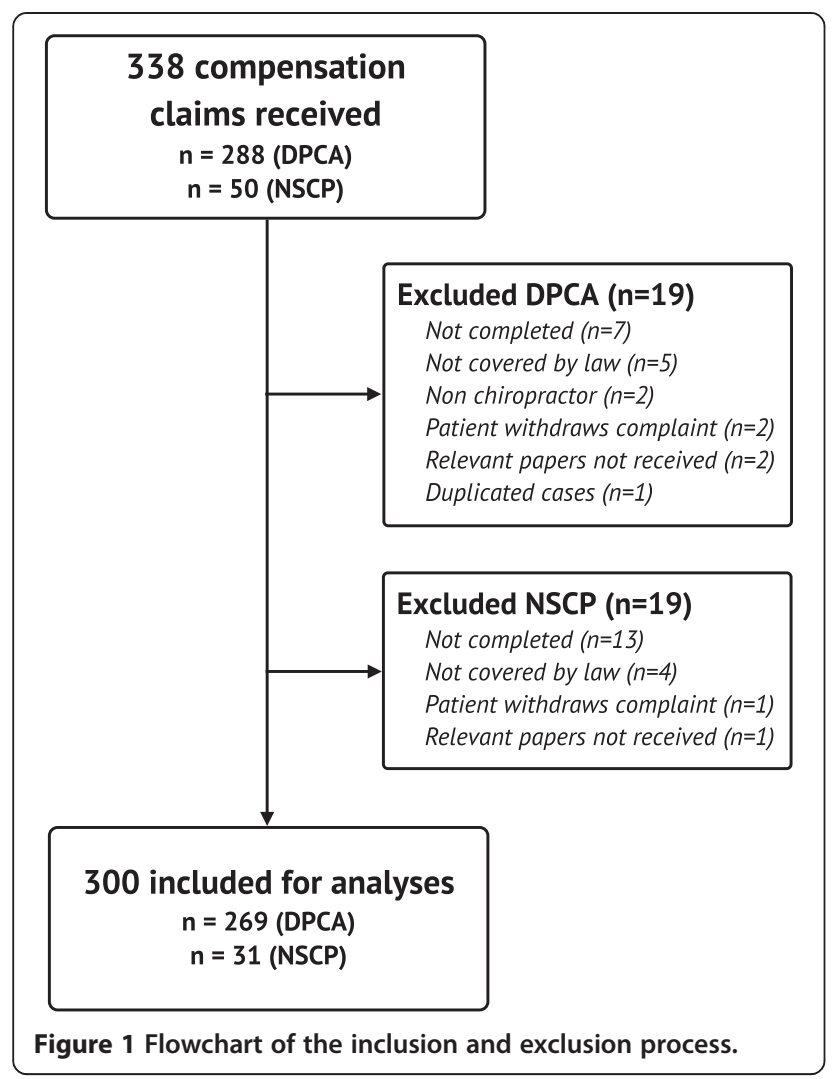

The most frequent complaint categories were 91 (30.3\%) cases of worsening symptoms following treatment, 57 (19\%) cases of alleged disk herniations and 46 (15.3\%) cases of delayed referral. Thus, these subgroups comprised 194. (65\%) of the 300 claims. A total financial payment of $€ 2,305,757$ were distributed over the forty-one cases. The lowest compensation registered was $€ 390$ and the highest $€ 605,480$ (median $€ 7,730$, mean $€ 56,238$ ) (Table 2). Claims relating to treatment of specific body-regions included 93 (31\%) claims after treatment to the cervical spine (31\%),
$48(16 \%)$ to the thoracic spine and $118(39.3 \%)$ to the lumbar spine (Table 3).

Out of the 300 included cases, a total of 84 appeals were registered. 71 (84.5\%) decisions remained unchanged after appeal, $8(61.5 \%)$ complaints that were originally rejected ended in favour of the patient and $5(38.5 \%)$ in favour of the compensation associations. Of the 41 approved appeals, $32(78 \%)$ were directly approved after appraisal. In one case (2.5\%) an appeal for a higher compensation was filed but the payment remained unchanged but still approved for compensation for the original amount. The remaining 8 cases $(19.5 \%)$ were approved after appeals.

\section{Discussion}

This is the first study to provide a detailed description of compensation claims related to chiropractic treatment reported in Denmark and Norway. During 2004-2012 we were able to describe 300 of a total of 338 claims, only 41 of these were approved for compensation. A fairly stable rate of claims was observed, about thirty and twelve per year in Denmark and Norway, and the annual approval rate remained about $15 \%$ across the period.

Children under ten years of age regularly consult chiropractors $[37,38]$ and Danish data suggests that $35 \%$ of patients in this age group are infants [37]. Paediatric treatment delivered by chiropractors remains a controversial topic within the medical literature [39]. Interestingly, our data did not reveal a single claim in this age group for both countries.

At the other end of the age spectrum, current data indicates that more than $20 \%$ of patients in chiropractic practice are over 60 years old [37]. In this study 37 claims were reported from this age group, representing $12.3 \%$ of the total amount. The United Nations predict that the proportion of people aged 60 years and over will triple over the next 40 years and will account for more

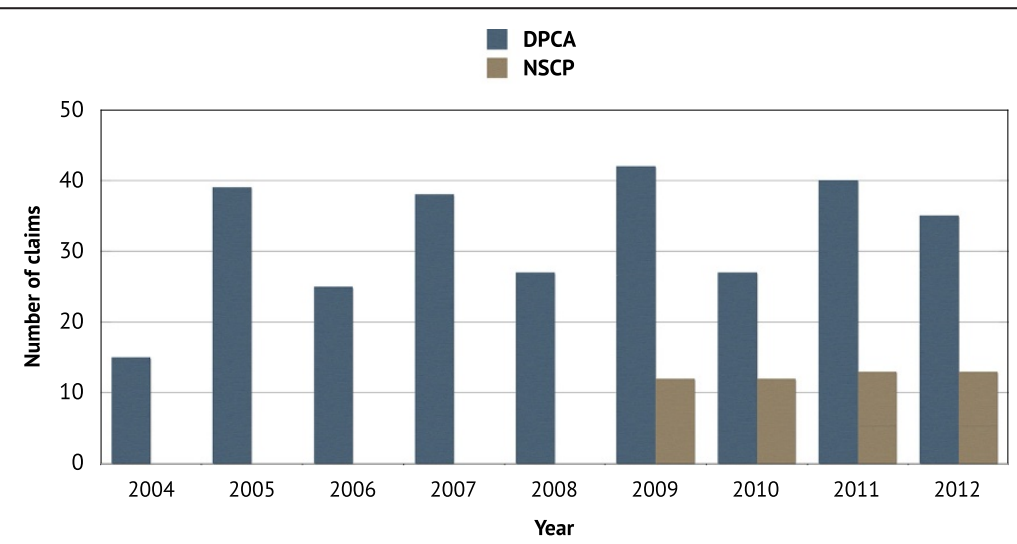

Figure 2 Number of reported claims per year 2004 to 2012. Number of annually reported claims to the two compensation associations since their respective inception. 


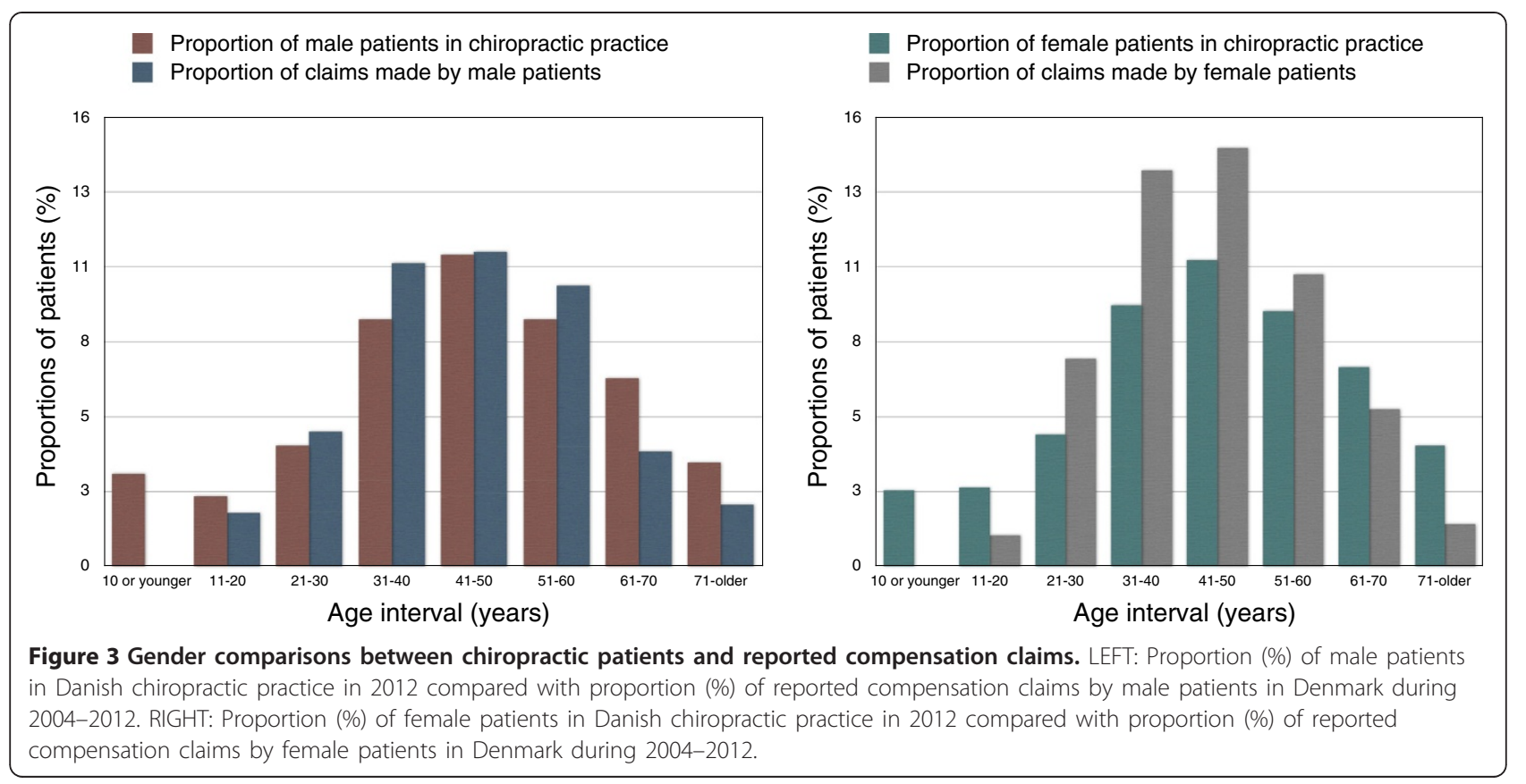

than $20 \%$ of the world's population by year 2050 [40]. Manifestations of musculoskeletal disorders increase with age [41] making interventions with documented effect and a favourable risk profile desirable [42]. In one recent study investigating the effectiveness of SMT and exercise interventions among seniors (aged 65 and above) with chronic neck pain [43] information on $\mathrm{AE}$ was systematically collected [44]. The AE identified were primarily musculoskeletal or pain related and non-serious and this is consistent with current evidence on AE following SMT and exercise $[15,19,24,45]$ suggesting that these interventions have a lower risk of harm relative to other commonly used pharmacological interventions for neck pain [42].

Several types of compensation claims were reported following chiropractic treatment, however it appears that many complaints were filed because of unrealistic expectations to treatment effect or because the clinicians did

Table 1 Overview of annual decisions

\begin{tabular}{|c|c|c|c|c|c|c|c|c|c|c|c|}
\hline & 2004 & 2005 & 2006 & 2007 & 2008 & 2009 & 2010 & 2011 & 2012 & 2013 & Total \\
\hline \multicolumn{12}{|l|}{ DPCA } \\
\hline Number of decisions & 4 & 17 & 25 & 28 & 44 & 29 & 38 & 17 & 53 & 14 & 269 \\
\hline Approved/rejected & $1 / 3$ & $2 / 15$ & $5 / 20$ & $7 / 21$ & $6 / 38$ & $4 / 25$ & $3 / 35$ & $2 / 15$ & $7 / 46$ & $2 / 12$ & $39 / 230$ \\
\hline Approval percent & $25 \%$ & $11,8 \%$ & $20 \%$ & $25 \%$ & $13,6 \%$ & $13,8 \%$ & $7,9 \%$ & $11,8 \%$ & $13,2 \%$ & $14,3 \%$ & $15.6 \%$ \\
\hline Financial compensation (€EUR) & $€ 240,630$ & $€ 171,344$ & $€ 630,468$ & $€ 57,342$ & $€ 555,566$ & $€ 66,875$ & $€ 20,848$ & $€ 441,813$ & $€ 43,457$ & $€ 24,374$ & $€ 2,252,717$ \\
\hline \multicolumn{12}{|l|}{ NSCP } \\
\hline Number of decisions & & & & & & 0 & 8 & 11 & 6 & 6 & 31 \\
\hline Approved/rejected & & & & & & 0 & $0 / 8$ & $1 / 10$ & $1 / 5$ & $0 / 6$ & $2 / 29$ \\
\hline Approval percent & & & & & & 0 & 0 & 9,1 & 16,7 & 0 & $5.2 \%$ \\
\hline Financial compensation (€EUR) & & & & & & $€ 0$ & $€ 0$ & $€ 1,440$ & $€ 51,600$ & $€ 0$ & $€ 53,040$ \\
\hline \multicolumn{12}{|l|}{ TOTAL } \\
\hline Number of decisions & 4 & 17 & 25 & 28 & 44 & 29 & 46 & 28 & 59 & 20 & 300 \\
\hline Approved/rejected & $1 / 3$ & $2 / 15$ & $5 / 20$ & $7 / 21$ & $6 / 38$ & $4 / 25$ & $3 / 43$ & $3 / 25$ & $8 / 51$ & $2 / 18$ & $41 / 259$ \\
\hline Approval percent & 25,0 & 11,8 & 20,0 & 25,0 & 13,6 & 13,8 & 6,5 & 10,7 & 13,6 & 10,0 & $13.7 \%$ \\
\hline Financial compensation (€EUR) & $€ 240,630$ & $€ 171,344$ & $€ 630,468$ & $€ 57,342$ & $€ 555,566$ & $€ 66,875$ & $€ 20,848$ & $€ 443,253$ & $€ 95,057$ & $€ 24,374$ & $€ 2,305,757$ \\
\hline
\end{tabular}

Annual number of decisions, approvals and financial compensations in Denmark and Norway from 2004 to 2013. 
Table 2 Overview of complaint categories

\begin{tabular}{llll}
\hline Complaint category & $\begin{array}{l}\text { Total } \\
\mathbf{n}(\%)\end{array}$ & $\begin{array}{l}\text { Approved } \\
\mathbf{n}(\%)\end{array}$ & $\begin{array}{l}\text { Financial compensation } \\
\text { €EUR (\% of total) }\end{array}$ \\
\hline $\begin{array}{l}\text { Worsening pain } \\
\text { following treatment }\end{array}$ & $91(30.3 \%)$ & $5(5.5 \%)$ & $€ 23,483(1 \%)$ \\
Alleged disk herniation & $57(19 \%)$ & $2(3.5 \%)$ & $€ 30,295(1.3 \%)$ \\
Delayed referral & $46(15.3 \%)$ & $14(30.4 \%)$ & $€ 148,667(6.4 \%)$ \\
Newly developed & $35(11.7 \%)$ & $3(8.6 \%)$ & $€ 12,537(0.5 \%)$ \\
symptoms/injury & $18(6 \%)$ & $3(16.7 \%)$ & $€ 20,612(0.9 \%)$ \\
Fracture & $17(5.7 \%)$ & $11(64.7 \%)$ & $€ 2,044,523(88.7 \%)$ \\
Cervical artery dissection & $11(3.7 \%)$ & $0(0 \%)$ & $€ 0(0 \%)$ \\
Rib injury & $10(3.3 \%)$ & $1(10 \%)$ & $€ 3,441(0.1 \%)$ \\
Accidents & $15(5.0 \%)$ & $2(13.3 \%)$ & $€ 22,199(1 \%)$ \\
Miscellaneous & $300(100 \%)$ & $41(13.7 \%)$ & $€ 2,305,757$ \\
\hline TOTAL &
\end{tabular}

Complaint categories, approval rates and financial compensation based on total amount of claims from DPCA and NSCP.

not inform the patients about commonly occurring benign reactions to treatment. This is highlighted by the fact that three of the most frequent subgroups were "worsening symptoms", "alleged disk herniation" and "newly developed symptoms" comprising 183 (61\%) of the total complaints with only $10(5.5 \%)$ being approved. While many patients seem to blame their symptoms on the treatment, it is probably due to the natural course of their underlying condition (i.e. degenerative joint disease) or non-specific effects, as supported by a recent randomized trial where the authors concluded that many of the normal AE seen following chiropractic care may be due to natural history variation and non-specific effects [30]. Therefore many complaints may be preventable if thorough and adequate information is given prior to delivering treatment.

Manual treatment of the cervical spine remains a controversial topic in health care [20,21]. In our data,

Table 3 Primary treated body region

\begin{tabular}{lll}
\hline Body region & $\begin{array}{l}\text { Total } \mathbf{n}(\%) / A p p r o v e d \\
\mathbf{n}(\%)\end{array}$ & $\begin{array}{l}\text { Financial compensation } \\
\text { €EUR (\% of total) }\end{array}$ \\
\hline Cervical spine & $93(31 \%) / 18(19.4 \%)$ & $€ 2,107,271(91.5 \%)$ \\
Thoracic spine & $48(16 \%) / 4(8.3 \%)$ & $€ 18,236(0.8 \%)$ \\
Lumbar Spine & $118(39.3 \%) / 14(11.9 \%)$ & $€ 150,462(6.5 \%)$ \\
Cervical and & $3(1 \%) / 0(0 \%)$ & $€ 0(0 \%)$ \\
lumbar spine & & \\
Upper extremity & $15(5 \%) / 2(13.3 \%)$ & $€ 9,359(0.4 \%)$ \\
Lower extremity & $10(3.3 \%) / 1(10 \%)$ & $€ 8,924(0.4 \%)$ \\
Accidents & $10(3.3 \%) / 1(10 \%)$ & $€ 3,441(0.1 \%)$ \\
Non-specified & $3(1 \%) / 1(33.3 \%)$ & $€ 8,064(0.4 \%)$ \\
Total & $300(100 \%) / 41(13.7 \%)$ & $€ 2,305,757$
\end{tabular}

Complaints stratified by body region primary treated in relation to approvals and financial compensations based on total number of claims from DPCA and NSCP.
91 cases (31\%) were based on complaints after manual treatment to the cervical spine and 18 were approved. A particular concern after cervical SMT is dissection of the vertebral and carotid arteries [46]. Seventeen claims concerning CAD were reported in this data, 14 in Denmark and three in Norway, and 11 of these were approved for financial compensation (64.7\% approval rate) representing by far the highest approval rate across all complaint categories. All eleven approved claims were in Denmark, and all complaints were approved based on the rule of reason that does not imply causality. In Norway, however, all three cases were rejected because the clinician had displayed sound clinical judgement and because no contraindications for manual treatment were found. This illustrates the difference in the assessment of complaints between the two countries, as cases in Denmark are approved for compensation even though treatment is consistent with clinical guidelines and specialist standard. Interestingly, if CAD cases were excluded from this data the overall approval rate would decrease from $13.7 \%$ to $10.6 \%$ and the financial compensations would decrease by almost $90 \%$. Furthermore, while the mean financial compensation was $€ 56,238$, the median payment was $€ 7,730$ illustrating that compensation for CAD to a large extent drives the cost of compensation at least in Denmark. Lastly, of the eleven approved CAD claims, five were reimbursed a total of $€ 68,175$, indicating that these were fairly mild with regards to affected workability and disability. The remaining six cases thus represented 97\% of the financial compensation in this category.

Cases of delayed referral constitute the second most important subgroup with regards to approval rates with a total of forty-six claims and 14 (30.4\%) approved cases. These claims consisted primarily of cases where the clinician had failed to act upon clear signs of nerve root compression, i.e. paresis and/or cauda equina syndrome, or did not refer for diagnostic imaging in spite of a clear indication. Furthermore, several cases in this category were approved because the clinician did not deliver adequate patient records resulting in approval in favour of the patient. In addition, many case files showed several examples of incomplete examinations and poor clinical judgment.

Norwegian (The Norwegian Health Economics Administration: Chiropractic services in Norway 2012, unpublished) and Danish chiropractors both deliver approximately two million consultations annually [37]. They receive on average 42 claims combined suggesting roughly one claim per 100.000 consultations. By comparison, Danish statistics show that in the period 2007-2012 chiropractors, GPs and physiotherapists (+ occupational therapists) received 1.76, 1.32 and 0.52 claims per 100.000 consultations, respectively $[35,37]$ with approval rates of $13 \%, 25 \%$ and $21 \%$, respectively. During this period these 
three groups were reimbursed on average $€ 58,000$, $€ 29,000$ and $€ 18,000$ per approved claim, respectively. Interestingly, while chiropractors generally seem to receive more claims per consultation than GPs and physiotherapists, the approval rate is substantially lower [35] and a similar trend is observed in Norway [36]. However, it is also evident that approved claims within chiropractic bear a higher financial burden than their peers. These numbers are clearly highly influenced by the cases related to CAD. Several reasons might explain a higher complaint rate within chiropractic but this remains speculation and we do not have hard evidence supporting any of the following suggestions: (1) chiropractic treatment might be perceived as more aggressive than that of GPs and physiotherapists (2) maybe scepticism towards chiropractic among medical physicians and physiotherapists could encourage more patient complaints (3) a higher out-of-pocket expense for chiropractic services compared with GP and physiotherapist services might influence the higher number of complaints (4) chiropractors do not adequately inform patients about normal side effects and reactions and patients regard these as serious and relevant for compensation claims (5) chiropractors encourage patients to report $\mathrm{AE}$ more frequently than GPs and physiotherapists.

\section{Strengths and limitations}

The strengths of this study were that it included all filed compensation claims concerning chiropractic treatment reported to the two national compensation associations since their inception. As most studies related to MT primarily focus on treatment effects, this study provides important insights into what types of reactions chiropractic patients file as injuries to compensation bodies. One could expect the Norwegian numbers to increase in the coming years, as the registration system is still in its infancy whereas Danish data likely reflect the natural or "steady state" level within this particular system. Of importance, DPCA recently released its annual report for 2013, showing that complaints rates for GPs and physiotherapists have increased since 2011, while complaint rates for chiropractors have decreased. In addition, approval rates for chiropractors and physiotherapists have decreased in this period, while approval rates for GPs have remained stable [47].

Due to certain data missing and the small number of cases, a detailed analysis of chiropractor and treatment characteristics was not possible. Therefore we cannot assess whether differences in age, sex, educational background or years in practice influence the results and no pattern of injury reporting across these domains can be explored. Furthermore, no assessment around types of treatment and its relation to the $\mathrm{AE}$ reported was possible because exact description of the treatment was mostly absent. On the other hand one could argue that this reporting is pragmatic, as most chiropractors include several different interventions on most patients, including SMT, mobilization, exercise and different softtissue modalities [30]. Consequently, it would probably not be possible to discern which part of the treatment package was responsible for the compliant. Finally, because of the descriptive and retrospective nature of this paper, we cannot conclude on causality between the delivered treatment and the reported claims.

\section{Clinical and research implications}

At this point it seems clear that a large portion of patients will experience minor AE during a course of chiropractic treatment $[16,24,27,30]$. For this reason chiropractors need to devote time to explain this to patients and emphasize that these are not AE but normal benign reactions to the manual treatment. While the causality between MT and CAD remains uncertain [20,21,48-50], these events will continue to occur in association with cervical spine manipulation. Evidence-based frameworks for early identification of CAD have recently been published [51] and we encourage clinicians to stay up-todate on the evolving evidence surrounding CAD. As for cases of delayed referral, we can only recommend clinicians to stay vigilant and prioritize thorough and reasoned clinical examinations.

From a research perspective, it seems that chiropractors experience a higher rate of complaints following treatments when compared to physiotherapists and GPs. The reasons for this remain unknown, and thus qualitative research into these questions is of interest. Furthermore, we strongly support the implementation of incident reporting in chiropractic practice, and recently initiatives have been made in countries such as Switzerland and England. Although DPCA and NSCP are unique organizations in Europe, we suspect that more knowledge can be gained through more systematic collection of reported adverse events in chiropractic practice [52] as well as in medicine in general [3].

\section{Conclusion}

The overall rate of compensation claims for chiropractors in Denmark and Norway is on par with GPs and physiotherapists and only a small proportion of claims result in compensation. Chiropractors in both countries receive more claims than GPs and physiotherapists but the approval rate is substantially lower. Many claims can probably be prevented if chiropractors would prioritize informing patients about the normal course of their complaint and normal benign reactions to treatment.

\section{Competing interests}

The authors declare that they have no competing interests. 


\section{Authors' contributions}

All authors were responsible for the design of the study. JJ performed the data collection, analyses and was responsible for drafting the manuscript. All authors contributed to subsequent revisions of the manuscript and all read and approved the final version

\section{Acknowledgements}

The authors would like to thank the The Danish Patient Compensation Association and the Norwegian System of Compensation to Patients. More specifically Kim Lyngby Mikkelsen for organizing and providing data from DPCA and Henrik Adamsen, office manager at DPCA Odense, for kindly providing office space during the preparation and execution of this study. Furthermore, a thank you to Mette Willumstad Thomsen at NSCP for providing data and kindly answering numerous emails and requests during this process.

\section{Author details}

'Hønefoss Kiropraktikk og Rehabilitering, Torvgata 2, 3513 Hønefoss, Norway. ${ }^{2}$ Department of Sports Science and Clinical Biomechanics, Faculty of Health Sciences, University of Southern Denmark, Campusvej 55, DK-5230 Odense M, Denmark. ${ }^{3}$ Nordic Institute of Chiropractic and Clinical Biomechanics, Campusvej 55, DK-5230 Odense M, Denmark.

Received: 28 May 2014 Accepted: 21 October 2014

Published online: 07 November 2014

\section{References}

1. loannidis JP: Adverse events in randomized trials: neglected, restricted, distorted, and silenced. Arch Intern Med 2009, 169:1737-1739.

2. McIntosh HM, Woolacott NF, Bagnall AM: Assessing harmful effects in systematic reviews. BMC Med Res Methodol 2004, 4:19.

3. Zorzela L, Golder S, Liu Y, Pilkington K, Hartling L, Joffe A, Loke Y, Vohra S: Quality of reporting in systematic reviews of adverse events: systematic review. BMJ 2014, 348:f7668.

4. Pitrou I, Boutron I, Ahmad N, Ravaud P: Reporting of safety results in published reports of randomized controlled trials. Arch Intern Med 2009, 169:1756-1761.

5. Ohrn A, Olai A, Rutberg H, Nilsen P, Tropp H: Adverse events in spine surgery in Sweden: a comparison of patient claims data and national quality register (Swespine) data. Acta Orthop 2011, 82:727-731.

6. Spaans AJ, van den Hout JA, Bolder SB: High complication rate in the early experience of minimally invasive total hip arthroplasty by the direct anterior approach. Acta Orthop 2012, 83:342-346.

7. Bystrom S, Espehaug B, Furnes O, Havelin LI, Norwegian Arthroplasty R: Femoral head size is a risk factor for total hip luxation: a study of 42,987 primary hip arthroplasties from the Norwegian Arthroplasty Register. Acta Orthop Scand 2003, 74:514-524.

8. Lohana P, Woodnutt DJ, Boyce DE: Sciatic nerve palsy-a complication of posterior approach using enhanced soft tissue repair for total hip arthroplasty. J Plast Reconstr Aesthet Surg 2010, 63:e400-e401.

9. SooHoo NF, Lieberman JR, Ko CY, Zingmond DS: Factors predicting complication rates following total knee replacement. J Bone Joint Surg Am 2006, 88:480-485.

10. Coombes BK, Bisset L, Vicenzino B: Efficacy and safety of corticosteroid injections and other injections for management of tendinopathy: a systematic review of randomised controlled trials. Lancet 2010, 376:1751-1767.

11. Scott A, Khan KM: Corticosteroids: short-term gain for long-term pain? Lancet 2010, 376:1714-1715.

12. Coxib and traditional NSAID Trialists' (CNT) Collaboration, Bhala N, Emberson J, Merhi A, Abramson S, Arber N, Baron JA, Bombardier C, Cannon C, Farkouh ME, FitzGerald GA, Goss P, Halls H, Hawk E, Hawkey C, Hennekens C, Hochberg M, Holland LE, Kearney PM, Laine L, Lanas A, Lance P, Laupacis A, Oates J, Patrono C, Schnitzer TJ, Solomon S, Tugwell P, Wilson K, Wittes J, et al: Vascular and upper gastrointestinal effects of non-steroidal antiinflammatory drugs: meta-analyses of individual participant data from randomised trials. Lancet 2013, 382:769-779.

13. Hahne AJ, Ford JJ, Hinman RS, Taylor NF, Surkitt LD, Walters AG, McMeeken JM: Outcomes and adverse events from physiotherapy functional restoration for lumbar disc herniation with associated radiculopathy. Disabil Rehabil 2011, 33:1537-1547.
14. Carlesso LC, Macdermid JC, Santaguida PL, Thabane L: Determining adverse events in patients with neck pain receiving orthopaedic manual physiotherapy: a pilot and feasibility study. Physiother Can 2013, 65:255-265.

15. Liu CJ, Latham N: Adverse events reported in progressive resistance strength training trials in older adults: 2 sides of a coin. Arch Phys Med Rehabil 2010, 91:1471-1473.

16. Paanalahti K, Holm LW, Nordin M, Asker M, Lyander J, Skillgate E: Adverse events after manual therapy among patients seeking care for neck and/or back pain: a randomized controlled trial. BMC Musculoskelet Disord 2014, 15:77.

17. Carnes D, Mars TS, Mullinger B, Froud R, Underwood M: Adverse events and manual therapy: a systematic review. Man Ther 2010, 15:355-363.

18. Bronfort $G$, Haas M, Evans R, Leininger B, Triano J: Effectiveness of manual therapies: the UK evidence report. Chiropr \& Osteopat 2010, 18:3.

19. Carlesso LC, Gross AR, Santaguida PL, Burnie S, Voth S, Sadi J: Adverse events associated with the use of cervical manipulation and mobilization for the treatment of neck pain in adults: a systematic review. Man Ther 2010, 15:434-444.

20. Cassidy JD, Bronfort G, Hartvigsen J: Should we abandon cervical spine manipulation for mechanical neck pain? No. BMJ 2012, 344:e3680.

21. Wand BM, Heine PJ, O'Connell NE: Should we abandon cervical spine manipulation for mechanical neck pain? Yes. BMJ 2012, 344:e3679.

22. Herzog W: The biomechanics of spinal manipulation. J Bodyw Mov Ther 2010, 14:280-286.

23. Hurwitz EL: Epidemiology: spinal manipulation utilization. J Electromyogr Kinesiol 2012, 22:648-654

24. Gouveia LO, Castanho P, Ferreira JJ: Safety of chiropractic interventions: a systematic review. Spine 2009, 34:E405-E413.

25. Hebert JJ, Stomski NJ, French SD, Rubinstein SM: Serious adverse events and spinal manipulative therapy of the low back region: a systematic review of cases. J Manip Physiol Ther 2013 [Epub ahead of print].

26. Smith WS, Johnston SC, Skalabrin EJ, Weaver M, Azari P, Albers GW Gress DR: Spinal manipulative therapy is an independent risk factor for vertebral artery dissection. Neurology 2003, 60:1424-1428.

27. Ernst E: Adverse effects of spinal manipulation: a systematic review. $J R$ Soc Med 2007, 100:330-338.

28. Wenban AB: Inappropriate use of the title 'chiropractor' and term 'chiropractic manipulation' in the peer-reviewed biomedical literature. Chiropr \& Osteopat 2006, 14:16.

29. Terrett AG: Misuse of the literature by medical authors in discussing spinal manipulative therapy injury. J Manip Physiol Ther 1995, 18:203-210

30. Walker BF, Hebert JJ, Stomski NJ, Clarke BR, Bowden RS, Losco B, French SD: Outcomes of usual chiropractic. The OUCH randomized controlled trial of adverse events. Spine 2013, 38:1723-1729.

31. Ernst $\mathrm{E}$, Resch KL: Concept of true and perceived placebo effects. BMJ 1995, 311:551-553.

32. Reuter U, Sanchez del Rio M, Carpay JA, Boes CJ, Silberstein SD, Program GSKHM: Placebo adverse events in headache trials: headache as an adverse event of placebo. Cephalalgia 2003, 23:496-503.

33. Wartolowska K, Judge A, Hopewell S, Collins GS, Dean BJ, Rombach I, Brindley D, Savulescu J, Beard DJ, Carr AJ: Use of placebo controls in the evaluation of surgery: systematic review. BMJ 2014, 348:93253.

34. Carnes D, Mullinger B, Underwood M: Defining adverse events in manual therapies: a modified Delphi consensus study. Man Ther 2010, 15:2-6.

35. Danish Patient Compensation Association: Årsberetninger (in Danish). Last accessed: 09.03.2014, [http://patienterstatningen.dk/da/Udgivelser-og-tal/ / media/Files/Statistik/Statistik\%202012/helårstal_2010_2012_12.ashx]

36. Norwegian System of Compensation to Patients: Statistikk for privat helsetjeneste 2009-2012 (in Norwegian) Last accessed: 09.03.2014, [http://www.npe.no/Documents/Rapporter/privat_rapport_2009_2012_web.pdf]

37. Statistics Denmark: Living conditions; health; visits to physicians. Last accessed: 09.03.2014, [http://www.statistikbanken.dk/statbank5a/default. asp?w=1440]

38. Hestbaek L, Jorgensen A, Hartvigsen J: A description of children and adolescents in Danish chiropractic practice: results from a nationwide survey. J Manip Physiol Ther 2009, 32:607-615.

39. Aase K, Blaakaer J: [Chiropractic care of infants with colic lacks evidence] Ugeskr Laeger 2013, 175:424-428.

40. United Nations: World Population Ageing. New York; 2009 
41. Fejer $\mathrm{R}$, Ruhe $\mathrm{A}$ : What is the prevalence of musculoskeletal problems in the elderly population in developed countries? A systematic critical literature review. Chiropr Man Therap 2012, 20:31.

42. Abdulla A, Adams N, Bone M, Elliott AM, Gaffin J, Jones D, Knaggs R, Martin D, Sampson L, Schofield P, British Geriatric S: Guidance on the management of pain in older people. Age Ageing 2013, 42(Suppl 1):i1-i57.

43. Maiers M, Bronfort G, Evans R, Hartvigsen J, Svendsen K, Bracha Y, Schulz C, Schulz K, Grimm R: Spinal manipulative therapy and exercise for seniors with chronic neck pain. Spine J 2014, 14:1879-1889.

44. Maiers M, Evans R, Hartvigsen J, Schultz C, Bronfort G: Adverse events among seniors receiving spinal manipulation and exercise in a randomized clinical trial. Man Ther 2014, In press.

45. Rubinstein SM: Adverse events following chiropractic care for subjects with neck or low-back pain: do the benefits outweigh the risks? J Manip Physiol Ther 2008, 31:461-464.

46. Debette S: Pathophysiology and risk factors of cervical artery dissection: what have we learnt from large hospital-based cohorts? Curr Opin Neurol 2014, 27:20-28.

47. Danish Patient Compensation Association: Helårsstatistik 2013 (in Danish). Last accessed: 09.03.2014, [http://patienterstatningen.dk/da/Udgivelser-og-tal/ / media/Files/Aarsberetninger/Aaret\%202013/BHskaderendeligversion2013.ashx]

48. Haynes MJ, Vincent K, Fischhoff C, Bremner AP, Lanlo O, Hankey GJ: Assessing the risk of stroke from neck manipulation: a systematic review. Int J Clin Pract 2012, 66:940-947.

49. Wynd S, Westaway M, Vohra S, Kawchuk G: The quality of reports on cervical arterial dissection following cervical spinal manipulation. PLoS One 2013, 8:e59170.

50. Chung CL, Cote P, Stern P, L'Esperance G: The association between cervical spine manipulation and carotid artery dissection: a systematic review of the literature. J Manip Physiol Ther 2014 [Epub ahead of print].

51. Rushton A, Rivett D, Carlesso L, Flynn T, Hing W, Kerry R: International framework for examination of the cervical region for potential of cervical arterial dysfunction prior to orthopaedic manual therapy intervention. Man Ther 2014, 19:222-228.

52. Wangler M, Fujikawa R, Hestbaek L, Michielsen T, Raven TJ, Thiel HW, Zaugg B: Creating European guidelines for Chiropractic Incident Reporting and Learning Systems (CIRLS): relevance and structure. Chiropr Man Therap 2011, 19:9.

doi:10.1186/s12998-014-0037-4

Cite this article as: Jevne et al:: Compensation claims for chiropractic in Denmark and Norway 2004-2012. Chiropractic \& Manual Therapies 2014 22:37.

\section{Submit your next manuscript to BioMed Central and take full advantage of:}

- Convenient online submission

- Thorough peer review

- No space constraints or color figure charges

- Immediate publication on acceptance

- Inclusion in PubMed, CAS, Scopus and Google Scholar

- Research which is freely available for redistribution 